\title{
Surgical strategies for treatment of clinical T4 esophageal cancer in Japan
}

\author{
Kazuhiko Yamada 1,* , Kyoko Nohara', Naoki Enomoto', Hitomi Wake', Syusuke Yagi', Masayoshi Terayama', Daiki Kato', \\ Chizu Yokoi ${ }^{2}$, Yasushi Kojima², Hidetsugu Nakayama ${ }^{3}$, Norihiro Kokudo \\ ${ }^{1}$ Department of Surgery, National Center for Global Health and Medicine, Tokyo, Japan; \\ ${ }^{2}$ Department of Gastroenterology, National Center for Global Health and Medicine, Tokyo, Japan; \\ ${ }^{3}$ Department of Radiation Therapy, National Center for Global Health and Medicine, Tokyo, Japan.
}

\begin{abstract}
Definitive chemoradiation (dCRT) is the mainstay treatment for cStage IVa esophageal squamous cell carcinoma (ESCC) with good performance status (PS), according to standard practice guidelines. Salvage surgery may incur operation complications and risk of mortality. According to the esophageal cancer practice guidelines outlined by the Japan Esophageal Society, when a tumor is residual and recurrent, chemotherapy and palliative symptomatic treatment is continued. However, salvage operation has been selected as a therapeutic option for recurrent or residual tumors after dCRT. There is weak evidence for not recommending surgery for cStage IVa ESCC exhibiting residual disease following dCRT. It has been reported that during salvage surgery the only prognostic factor that is thought to be performed is complete resection (R0), but at the same time, salvage esophagectomy increases the incidence of postoperative complications and mortality. The phase II chemoselection study by Yokota T et al. in Japan showed that multidisciplinary treatment initiated by induction therapy, in which docetaxel is added to cisplatin and 5-fluorouracil, resulted in a good prognosis in the short term. In this review, we discuss the surgical strategy and future of unresectable clinical T4 (cT4) ESCC.
\end{abstract}

Keywords: esophageal squamous cell carcinoma, clinical T4 (cT4), definitive chemoradiation, salvage surgery, conversion surgery

\section{Introduction}

Esophageal cancer is one of the most malignant worldwide. In Western countries, adenocarcinoma is prevalent, however, in Eastern countries squamous cell carcinoma is more common than adenocarcinoma. Within the esophageal cancer practice guidelines outlined by the Japan Esophageal Society, assessment of the general condition and performance status (PS) of the patient is important for determining the treatment strategy for cStage IVa esophageal squamous cell carcinoma (ESCC). For patients exhibiting cStage IVa status with good PS, definitive chemoradiotherapy (dCRT) of greater than 50 Gy is used as a first mainstay and standard treatment to attempt curability (1-3). Figure 1 shows the algorithm for cStage IVa status in esophageal cancer practice guidelines as edited in 2017. When a tumor disappears following dCRT and exhibits complete response (CR), chemotherapy or follow-up is continued. On the other hand, when a tumor is residual and recurrent, chemotherapy and palliative symptomatic treatment remains ongoing.
However, salvage operations have been selected as a therapeutic option for recurrent or residual tumors after dCRT by esophageal surgeons. In Japanese practice guidelines, there is weak evidence to recommend salvage operation for cStage IVa ESCC exhibiting residual and recurrent disease after dCRT. When a local residual or recurrent tumor occurs after CRT intervention for ESCC, salvage surgery or endoscopic treatment may result in a better prognosis (4-8). It has been reported that during salvage surgery the only prognostic factor is thought to be correlated with complete resection (R0), however, salvage esophagectomy does increase incidence of postoperative complications and mortality.

In Western countries, palliative symptomatic therapy is the primary treatment for unresectable ESCC, and a salvage operation is rarely performed. The phase II chemoselection study by Yokota $\mathrm{T}$ et al. conducted in Japan entailed multidisciplinary treatment started by induction therapy (chemoselection), in which docetaxel was added to cisplatin and 5-fluorouracil (5-FU). The subsequent conversion surgery resulted in a good shortterm prognosis (9). In contrast, the Kitasato digestive 


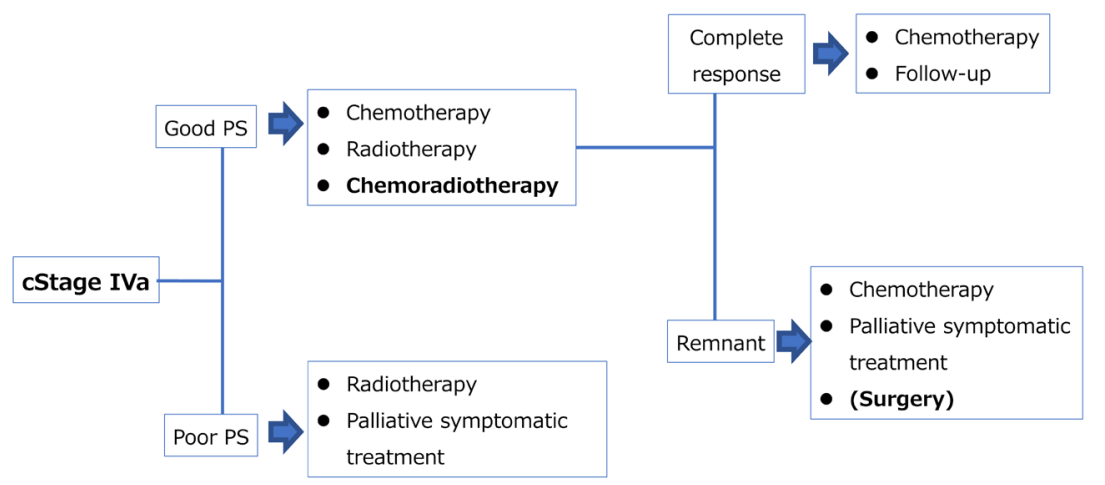

Figure 1. Esophageal cancer practice guidelines edited by the Japan Esophageal Society (JES), 2017. PS, performance status.

Table 1. Representative definitive CRT regimen for cT4 ESCC in Japan

\begin{tabular}{|c|c|c|c|c|c|c|c|}
\hline Year & Trial name & Drugs & Regimen & RT dose (Gy) & CR rate $(\%)$ & Survival & Ref. \\
\hline 1999 & & $\mathrm{CF}$ & $\begin{array}{l}\text { 5-FU } 400 \mathrm{mg} / \mathrm{m}^{2}, \mathrm{~d} 1-5,8-12,29-33,36-40, \text { CDDP } 75 \mathrm{mg} / \mathrm{m}^{2} \text {, } \\
\mathrm{d} 1,29\end{array}$ & 60 & 33 & 5 years: $14 \%$ & (12) \\
\hline 2004 & JCOG9516 & $\mathrm{CF}$ & 5-FU 700 mg/m², d1-4, 29-32, CDDP 75 mg/m², d1, 29 & 60 & 15 & 2 years: $31.5 \%$ & (13) \\
\hline 2015 & JCOG0303 & $\mathrm{CF}$ & $5-\mathrm{FU} 700 \mathrm{mg} / \mathrm{m}^{2}, \mathrm{~d} 1-4,29-32, \mathrm{CDDP} 70 \mathrm{mg} / \mathrm{m}^{2}, \mathrm{~d} 1,29$ & 60 & 0 & 2 years: $25.9 \%$ & (14) \\
\hline & & $\mathrm{CF}$ & $\begin{array}{l}\text { 5-FU } 200 \mathrm{mg} / \mathrm{m}^{2}, \mathrm{~d} 1-5,8-12,15-19,22-26,29-33, \text { CDDP } 4 \\
\mathrm{mg} / \mathrm{m}^{2}, \mathrm{~d} 1,29\end{array}$ & 60 & 1.4 & 2 years: $25.7 \%$ & (14) \\
\hline 2014 & KDOG0501 & DCF & $\begin{array}{l}\text { 5-FU } 400 \mathrm{mg} / \mathrm{m}^{2}, \mathrm{~d} 1-5,15-19,29-33,43-47, \text { CDDP } 40 \mathrm{mg} / \mathrm{m}^{2} \text {, } \\
\mathrm{d} 1,15,29,43 \text {, DOC } 20-40 \mathrm{mg} / \mathrm{m}^{2}, \mathrm{~d} 1,15,29,43\end{array}$ & $50.4-61.2$ & 42.1 & 1 year: $63.2 \%$ & $(10,15)$ \\
\hline
\end{tabular}

CRT: chemoradiation therapy; ESCC: esophageal squamous cell carcinoma; JCOG: Japan Clinical Oncology Group trial; KDOG: Kitasato Digestive Disease oncology Group trial; C: Cisplatin; F: 5-FU; D: Docetaxel.

disease oncology group (KDOG) 0501 phase I trial of docetaxel added to cisplatin and 5-fluorouracil (5FU) in combination with radiotherapy resulted in a CR rate of $42.1 \%(10)$. A new study (Japan Clinical Oncology Group (JCOG) 1510: TRIANgLE) is currently ongoing (11). Although it remains a challenging surgery, performing aortic stent insertion and total pharyngolaryngectomy with mediastinal tracheostomy is another option for intervention. In this review, we discuss surgical strategies and potential outcomes of unresectable clinical T4 (cT4) ESCC.

\section{Definitive chemoradiation data for unresectable esophageal squamous cell carcinoma}

In terms of recent esophageal cancer practice guidelines in Japan, the assessment of general condition and PS is important in making treatment decisions for cStage IVa ESCC. For patients exhibiting cStage IVa status with good PS, dCRT is the first mainstay treatment with an aim for curability $(1,2)$. This treatment regimen is standard for unresectable cT4 ESCC. Table 1 lists several clinical trials including unresectable cT4 ESCC in Japan.

Ohtsu et al. reported the efficacy of dCRT consisting of concurrent $60 \mathrm{~Gy}$ radiotherapy using cisplatin and 5-fluorouracil (CF) for cT4 and/or M1 lymph node (LYM) with ESCC (12). The rate of complete response (CR) was 33\% (18/54 patients) in a single-institution study. In 2004, the JCOG9516 study was reported as a phase II trial of dCRT for T4 and/or M1 LYM (13). The overall response rate was $68.3 \%$, with a CR rate of $15 \%$. Median survival time was 10 months and the 2-year survival rate was $31.5 \%$ in this multicenter trial. In 2015, another multicenter study (JCOG0303) was reported with a randomized phase II/III trial comparing standard $\mathrm{CF}$ versus a daily low-dose of $\mathrm{CF}$ with concurrent 60 Gy radiotherapy for treating cT4 unresectable regional lymph node metastasis (14). The median and 3-year overall survival rates of low-dose CF versus standard CF were 13.1 and 14.4 months, and $25.9 \%$ and $25.7 \%$, respectively. There was no obvious advantage incurred using a low-dose over the standard CF regimen. In 2008 and 2014, another study (KDOG0501) reported on a phase I/II trial evaluating the safety and efficacy of dCRT employed a docetaxel with CF (DCF) regimen (DCF-R) for T4 and/or M1LYM ESCC. The total radiation dose was initially set at $61.2 \mathrm{~Gy}$, but this was lowered to a multiple-field irradiation level of $50.4 \mathrm{~Gy}$. The overall CR rate was $52.4 \%: 33.3 \%$ in the 61.2 Gy group and $60.0 \%$ in the 50.4 Gy group. The median overall survival was 29.0 months and the 3 -year survival rate was $43.9 \%$. However, a major toxicity of Grade 3 or more occurred frequently $(10,15)$.

Salvage esophagectomy for local residual tumor after dCRT 


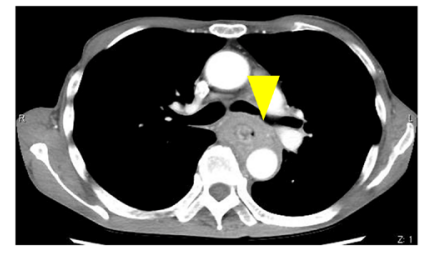

A

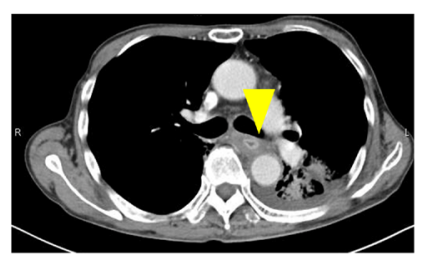

D

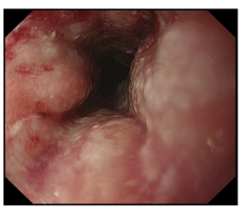

B

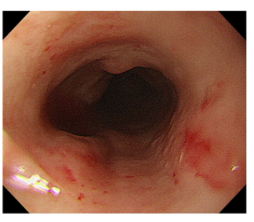

$\mathbf{E}$

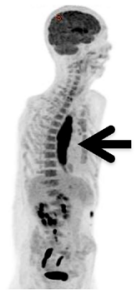

C

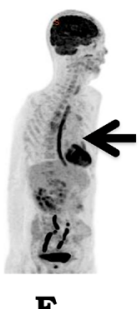

$\mathbf{F}$

Figure 2. A case of clinical T4 esophageal squamous cell carcinoma (ESCC) in pre-treatment status (A-C) and status after definitive chemoradiation therapy (dCRT) (D-F). (A) CT imaging of left bronchial level; (B) Endoscopic film of esophageal cancer; (C) ${ }^{18} \mathrm{~F}$-fluorodeoxyglucose-positron emission tomography (FDG-PET) scan of esophageal cancer; (D) CT imaging of left bronchial level; (E) Endoscopic film of esophageal cancer; (F) FDG-PET scan after dCRT.

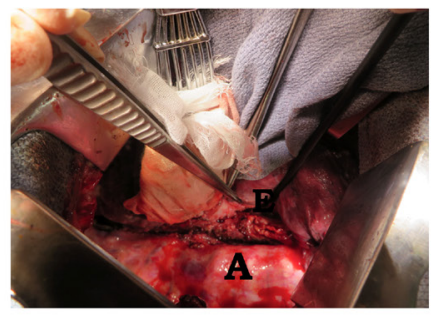

A

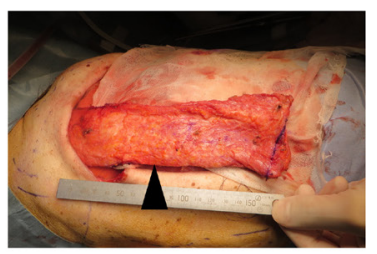

C

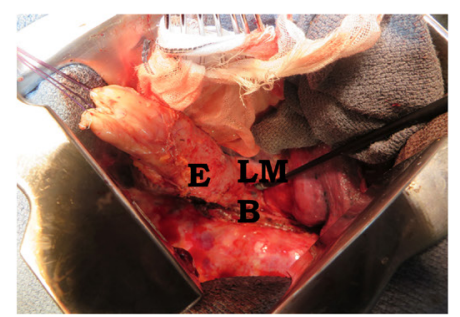

B

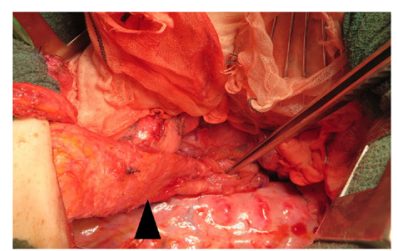

D

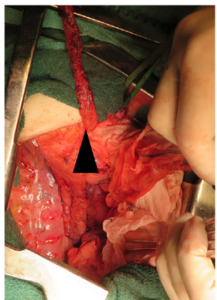

$\mathbf{E}$

Figure 3. Intraoperative findings of the same case wherein salvage esophagectomy with open thoracotomy was performed. Severe adhesion and fibrosis was observed, and the membrane between the esophagus and adjacent organs was unrecognizable (A). View after esophagectomy is shown in (B). A, Adhesion; E, Esophagus; LMB, left main bronchus. View of filling material available in muscles is shown in $(\mathbf{C}, \mathbf{D})$ latissimus dorsi and $(\mathbf{E})$ intercostal muscle.

In general, salvage surgery for local residual or recurrent tumors occurring after dCRT may increase the difficulty of operation and risk of mortality (18 ). However, this intervention is currently the only treatment leading to survival following dCRT. If dCRT is capable of R0 resection following induction CRT with 30-40 Gy irradiation using CF, we could perform esophagectomy, if required. However, deciding on the capability of surgical indications after induction CRT for cT4 ESCC is difficult. Furthermore, the recently introduced dCRT technique may improve outcomes more than induction CRT (16).
Figure 2 and Figure 3 describe a clinical case of salvage operation after dCRT. At first diagnosis the patient's clinical stage was cT4b (left main bronchus, aorta) N2M0 and cStage IVa status. First, the subject underwent dCRT using CF with a 60 Gy irradiation dose. After dCRT, the patient underwent two courses of chemotherapy with CF. Subsequently the residual tumor was of the thoracic esophagus, and ESCC was decreased (cT4bN2M0 $\rightarrow$ ycT2N0M0). We performed salvage esophagectomy and with open thoracotomy and laparotomy reconstructed by stomach roll. During the intraoperative findings, there was severe adhesion 
and fibrosis present, and the membrane between the esophagus and adjacent organs was unrecognizable (Figure 3A and 3B).

In Japan, the historical surgical treatment for unresectable cT4 ESCC has also changed over time from preoperative radiotherapy, combined resection of the adjacent organs with esophagectomy, and to dCRT with salvage surgery (6). However, preoperative radiation therapy and combined resection of the adjacent organs were not shown to be significant. At present, esophageal surgeons routinely perform salvage operation for removal of residual and remnant ESCC after dCRT, and there exists weak evidence within Japanese guidelines for Stage IVa ESCC due to surgery efficacy along with a high risk for mortality and morbidity.

Most surgeons have regarded adjacent organ invasion as indicative of poor prognosis and associated with high postoperative mortality and morbidity. There are two primary limitations of salvage esophagectomy for cT4 ESCC. First, the main prognostic factor is thought to be complete resection (R0). Intraoperative macroscopic inspection after dCRT is often unrecognizable. Secondly, preoperative assessment (e.g., imaging findings) entail limitations for predicting pathologic T4. The accuracy rates for detection of pathologic $\mathrm{T} 4$ and curability prediction following operation are insufficient. Only patients with definitive evidence of unresectability (R2) should be excluded from esophagectomy (8).

${ }^{18} \mathrm{~F}$-fluorodeoxyglucose-Positron emission tomography (FDG-PET) has been covered in national health insurance for esophageal cancer. In surgically resectable ESCC, the value of standardized uptake value (SUV) max of FDG-PET is effective for responders of neoadjuvant therapy. Recently, PET has proven to be an important modality for evaluation of treatment for T4 ESCC (17). Conversely, Jingu et al. reported that FDG -PET may not contribute to improving survival for locally advanced unresectable ESCC (18).

Many studies have reported about salvage esophagectomy for unresectable cT4 ESCC in Japan (19-34). Ikeda et al. reported on 13 of 37 patients after dCRT who underwent salvage surgery. R0 resection was performed in 12 patients (27). Another study protocol (JCOG0303) described chemoradiotherapy using CF with 60 Gy radiation for cT4 unresectable ESCC. Of the 71 patients who received dCRT, 12 cases $(17 \%)$ underwent salvage surgery for residual or recurrent tumors. The median overall survival was 13 months, and the 1 or 3 -year survival rates were $56.8 \%$ and $27.6 \%$, respectively. The prognoses of R1 and R2 patients were unfavorable (14). Ohkura et al. reported methods for lymph node dissection of salvage esophagectomy. If possible, salvage esophagectomy was performed with typical lymph node dissection, including prophylactic dissection, which led to improved prognosis (28). Pimiento et al. reported that historical incomplete resections and poor survival rates often result in surgery being palliative rather than curative. We have demonstrated that neoadjuvant therapy and downstaging of $\mathrm{T} 4$ tumors leads to increased $\mathrm{R} 0$ resections and improvements in overall and disease-free survival (21).

During salvage operations, the structure surrounding the esophagus and adjacent organs were unrecognizable during salvage operations for cT4 ESCC. These tissues bled easily and were fragile. In addition, it was impossible to distinguish cancer from severe fibrosis. Pathological diagnosis of intraoperative frozen sections at marginal lesions were sometimes diagnostically effective. The tracheal membranous portion was easily torn and damaged. If the boundary between the trachea and esophagus was undecipherable, the esophageal surgeon should have a filling material available (e.g., latissimus dorsi or intercostal muscles) (Figure 3C and $3 E)$. Surgeons should always be fully aware of when to return to the operation.

\section{Consensus of conversion surgery for unresectable ESCC}

Recently, induction chemotherapy is becoming available for intervention for unresectable cT4 ESCC. DCF induction chemotherapy for T4 ESCC reduced esophageal perforation and increased resectability and increased survival compared to CRT alone. Therefore, DCF induction chemotherapy may be an effective option for initial induction treatment of T4 ESCC (35-39). DCF and subsequent esophagectomy achieved $\mathrm{R} 0$ resection in $50 \%$ of patients and was associated with better longterm oncological outcomes for unresectable ESCC with acceptable systemic status (35). The available induction DCF chemotherapy for unresectable ESCC was considered from a trial of head and neck cancer. This strategy is known as conversion therapy and the related surgical intervention is termed conversion surgery. The clinical significance of conversion surgery for ESCC remains unknown. Yokota et al. reported on a multicenter phase II trial in which the safety and efficacy of chemoselection using induction chemotherapy with DCF for unresectable ESCC was assessed (9). Treatment was initiated with induction DCF, followed by conversion surgery for resectable tumors, or by CRT if tumors were unresectable. Twenty of the 48 patients enrolled (41.7\%) underwent conversion surgery and R0 resection was achieved in $39.6 \%$. The one-year overall survival rate had an improved prognosis of $67.9 \%$. These results suggest that chemo-selection with DCF induction chemotherapy followed by conversion surgery is a promising strategy for unresectable ESCC. At present, an ongoing trial is in phase III (JCOG1510) and compares two therapies: DCF induction versus dCRT plus salvage surgery (11).

Recently, challenging salvage operations were performed using thoracic endovascular aortic repair (TEVER) and salvage pharyngo-laryngectomy with mediastinal tracheostomy. TEVAR has been used for 


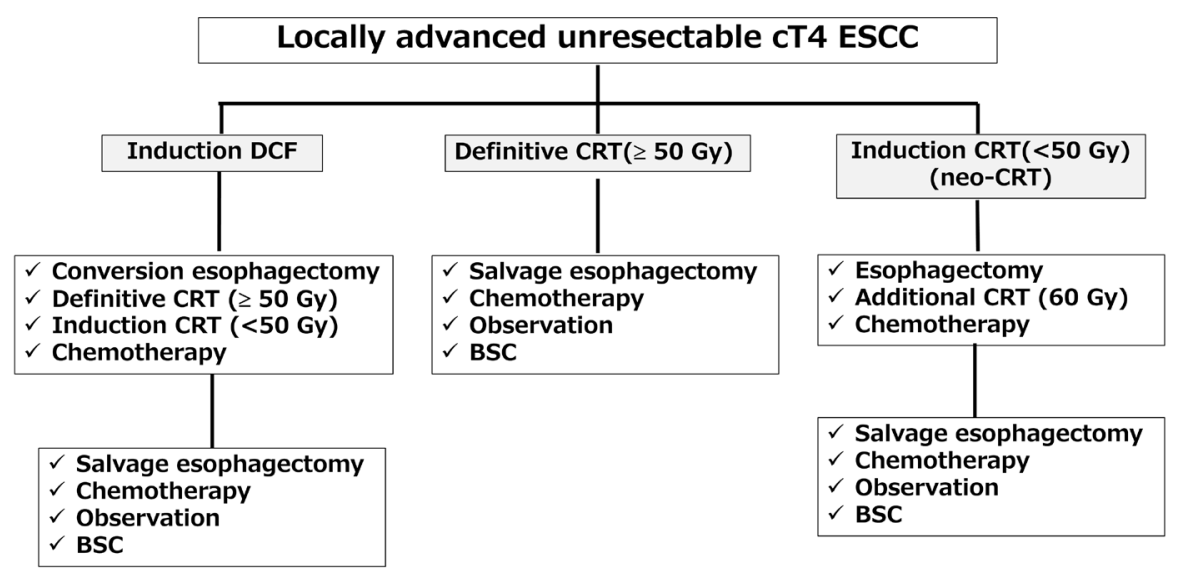

Figure 4. Surgical strategies for cT4 ESCC in Japan.

esophageal cancer invading the aorta to avoid esophagoaortic fistula. Nakajima et al. performed salvage esophagectomy combined with partial resection of the aortic wall after TEVAR in four patients following CRT, and acceptable short-term outcomes were obtained $(40,41)$.

\section{Conclusion}

In conclusion, we summarized the treatment algorism for unresectable cT4 ESCC (Figure 4). In the past, the prognosis for cT4 ESCC was poor because of limited therapy; however, induction chemotherapy (chemoselection) or DCF in combination with radiation therapy may result in better outcomes.

\section{Funding: None.}

Conflict of Interest: The authors have no conflicts of interest to disclose.

\section{References}

1. Kitagawa Y, Uno T, Oyama T, et al. Esophageal cancer practice guidelines 2017 edited by the Japan Esophageal Society: part 1. Esophagus. 2019; 16:1-24.

2. Kitagawa Y, Uno T, Oyama T, et al. Esophageal cancer practice guidelines 2017 edited by the Japan esophageal society: part 2. Esophagus. 2019; 16:25-43.

3. Watanabe M, Ohtake R, Kozuki R, Toihata T, Takahashi $\mathrm{K}$, Okamura A, Imamura Y. Recent progress in multidisciplinary treatment for patients with esophageal cancer. Surg Today. 2020; 50:12-20.

4. Makino T, Yamasaki M, Tanaka K, Miyazaki Y, Takahashi T, Kurokawa Y, Motoori M, Kimura Y, Nakajima K, Mori M, Doki Y. Treatment and clinical outcome of clinical T4 esophageal cancer: A systematic review. Ann Gastroenterol Surg. 2018; 3:169-180.

5. Seto Y, Chin K, Gomi K, Kozuka T, Fukuda T, Yamada K, Matsubara T, Tokunaga M, Kato Y, Yafune A, Yamaguchi T. Treatment of thoracic esophageal carcinoma invading adjacent structures. Cancer Sci. 2007; 98:937-942.
6. Fujita H, Sueyoshi S, Tanaka T, Tanaka Y, Matono S, Mori N, Shirouzu K, Yamana H, Suzuki G, Hayabuchi N, Matsui M. Esophagectomy: is it necessary after chemoradiotherapy for a locally advanced T4 esophageal cancer? Prospective nonrandomized trial comparing chemoradiotherapy with surgery versus without surgery. World J Surg. 2005; 29:25-31.

7. Akutsu Y, Matsubara H. Chemoradiotherapy and surgery for T4 esophageal cancer in Japan. Surg Today. 2015; 45:1360-1365.

8. Matsubara T, Ueda M, Kokudo N, Takahashi T, Muto T, Yanagisawa A. Role of esophagectomy in treatment of esophageal carcinoma with clinical evidence of adjacent organ invasion. Would J Surg. 2001; 25:279-284.

9. Yokota T, Kato K, Hamamoto Y, et al. Phase II study of chemoselection with docetaxel plus cisplatin and 5-fluorouracil induction chemotherapy and subsequent conversion surgery for locally advanced unresectable oesophageal cancer. Br J Cancer. 2016; 115:1328-1334.

10. Higuchi K, Komori S, Tanabe S, Katada C, Azuma M, Ishiyama H, Sasaki T, Ishido K, Katada N, Hayakawa K, Koizumi W; Kitasato Digestive Disease and Oncology Group. Definitive chemoradiation therapy with docetaxel, cisplatin, and 5-fluorouracil (DCF-R) in advanced esophageal cancer: a phase 2 trial (KDOG 0501-P2). Int J Radiat Oncol Biol Phys. 2014; 89:872-879.

11. Terada M, Hara H, Daiko H, Mizusawa J, Kadota T, Hori K, Ogawa H, Ogata T, Sakanaka K, Sakamoto T, Kato K, Kitagawa Y. Phase III study of tri-modality combination therapy with induction docetaxel plus cisplatin and 5-fluorouracil versus definitive chemoradiotherapy for locally advanced unresectable squamous cell carcinoma of the thoracic esophagus (JCOG1510: TRIANgLE). Jpn J Clin Oncol. 2019; 49:1055-1060.

12. Ohtsu A, Boku N, Muro K, Chin K, Muto M, Yoshida S, Satake M, Ishikura S, Ogino T, Miyata Y, Seki S, Kaneko K, Nakamura A. Definitive chemoradiotherapy for T4 and/or M1 lymph node squamous cell carcinoma of the esophagus. J Clin Oncol. 1999; 17:2915-2921.

13. Ishida K, Ando N, Yamamoto S, Ide H, Shinoda M. Phase II study of cisplatin and 5-fluorouracil with concurrent radiotherapy in advanced squamous cell carcinoma of the esophagus: a Japan Esophageal Oncology Group (JEOG)/ Japan Clinical Oncology Group trial (JCOG9516). Jpn J Clin Oncol. 2004; 34:615-619. 
14. Shinoda M, Ando N, Kato K, Ishikura S, Kato H, Tsubosa Y, Minashi K, Okabe H, Kimura Y, Kawano T, Kosugi S, Toh Y, Nakamura K, Fukuda H; Japan Clinical Oncology Group. Randomized study of low-dose versus standarddose chemoradiotherapy for unresectable esophageal squamous cell carcinoma (JCOG0303). Cancer Sci. 2015; 106:407-412.

15. Higuchi K, Komori S, Tanabe S, Katada C, Azuma M, Ishiyama H, Sasaki T, Ishido K, Katada N, Hayakawa K, Koizumi W; Kitasato Digestive Disease and Oncology Group. Definitive chemoradiation therapy with docetaxel, cisplatin, and 5-fluorouracil (DCF-R) in advanced esophageal cancer: a phase 2 trial (KDOG 0501-P2). Int J Radiat Oncol Biol Phys. 2014; 89:872-879.

16. Yamaguchi S, Morita M, Yamamoto M, Egashira A, Kawano H, Kinjo N, Tsujita E, Minami K, Ikebe M, Ikeda Y, Kunitake N, Toh Y. Long-term outcome of definitive chemoradiotherapy and induction chemoradiotherapy followed by surgery for T4 esophageal cancer with tracheobronchial invasion. Ann Surg Oncol. 2018; 25:3280-3287.

17. Makino T, Yamasaki M, Tanaka K, Tatsumi M, Takiguchi S, Hatazawa J, Mori M, Doki Y. Importance of positron emission tomography for assessing the response of primary and metastatic lesions to induction treatments in T4 esophageal cancer. Surgery. 2017; 162:836-845.

18. Jingu K, Umezawa R, Yamamoto T, akeda K, Ishikawa Y, Takahashi N, Kadoya N, Matsushita H. FDG-PET might not contribute to improving survival in patients with locally advanced inoperable esophageal cancer. Int J Clin Oncol. 2019; 24:927-933.

19. Ohira M, Kubo N, Masuda G, Yamashita Y, Sakurai K, Toyokawa T, Tanaka H, Muguruma K, Hirakawa K. Glasgow prognostic score as a prognostic clinical marker in T4 esophageal squamous cell carcinoma. Anticancer Res. 2015; 35:4897-4901.

20. Shimoji H, Karimata H, Nagahama M, Nishimaki T. Induction chemotherapy or chemoradiotherapy followed by radical esophagectomy for T4 esophageal cancer: results of a prospective cohort study. World J Surg. 2013; 37:2180-2188.

21. Pimiento JM, Weber J, Hoffe SE, Shridhar R, Almhanna K, Vignesh S, Karl RC, Meredith KL. Outcomes associated with surgery for T4 esophageal cancer. Ann Surg Oncol. 2013; 20:2706-2712.

22. Miyata H, Yamasaki M, Kurokawa Y, Takiguchi S, Nakajima K, Fujiwara Y, Mori M, Doki Y. Clinical relevance of induction triplet chemotherapy for esophageal cancer invading adjacent organs. J Surg Oncol. 2012; 106:441-447.

23. de Manzoni G, Pedrazzani C, Pasini F, Bernini M, Minicozzi AM, Giacopuzzi S, Grandinetti A, Cordiano C. Chemoradiotherapy followed by surgery for squamous cell carcinoma of the thoracic esophagus with clinical evidence of adjacent organ invasion. J Surg Oncol. 2007; 95:261-266.

24. Miyoshi N, Yano M, Takachi K, Kishi K, Noura S, Eguchi H, Yamada T, Miyashiro I, Ohue M, Ohigashi H, Sasaki Y, Ishikawa O, Doki Y, Imaoka S. Myelotoxicity of preoperative chemoradiotherapy is a significant determinant of poor prognosis in patients with T4 esophageal cancer. J Surg Oncol. 2009; 99:302-306.

25. Noguchi T, Moriyama H, Wada S, Takeno S, Wakisaka M, Mori H, Uchida Y. Resection surgery with neoadjuvant chemoradiotherapy improves outcomes of patients with
T4 esophageal carcinoma. Dis Esophagus. 2003; 16:9498.

26. Ikeda K, Ishida K, Sato N, Koeda K, Aoki K, Kimura Y, Iwaya T, Ogasawara S, Iijima S, Nakamura R, Uesugi N, Maesawa C, Saito K. Chemoradiotherapy followed by surgery for thoracic esophageal cancer potentially or actually involving adjacent organs. Dis Esophagus. 2001; 14:197-201.

27. Van Raemdonck D, Van Cutsem E, Menten J, Ectors N, Coosemans W, De Leyn P, Lerut T. Induction therapy for clinical T4 oesophageal carcinoma; a plea for continued surgical exploration. Eur J Cardiothorac Surg. 1997; 11:828-837.

28. Ohkura Y, Ueno M, Iizuka T, Udagawa H. Prognostic factors and appropriate lymph node dissection in salvage esophagectomy for locally advanced T4 esophageal cancer. Ann Surg Oncol. 2019; 26:209-216.

29. Sugawara K, Yagi K, Okumura Y, Nishida M, Aikou S, Yamashita H, Yamashita H, Seto Y. Long-term outcomes of multimodal therapy combining definitive chemoradiotherapy and salvage surgery for T4 esophageal squamous cell carcinoma. Int J Clin Oncol. 2020; 25:552560 .

30. Booka E, Haneda R, Ishii K, Kawakami T, Tsushima T, Yasui H, Onoe T, Ogawa H, Tsubosa Y. Appropriate candidates for salvage esophagectomy of initially unresectable locally advanced T4 esophageal squamous cell carcinoma. Ann Surg Oncol. 2020; 27:3163-3170.

31. Okamura A, Hayami M, Kozuki R, Takahashi K, Toihata T, Imamura Y, Mine S, Watanabe M. Salvage esophagectomy for initially unresectable locally advanced T4 esophageal squamous cell carcinoma. Esophagus. 2020; 17:59-66.

32. Taniyama TK, Tsuda T, Miyakawa K, Arai H, Doi A, Hirakawa M, Horie Y, Mizukami T, Izawa N, Ogura T, Sunakawa Y, Nakajima TE. Analysis of fistula formation of $\mathrm{T} 4$ esophageal cancer patients treated by chemoradiotherapy. Esophagus. 2020; 17:67-73.

33. Kawakami T, Tsushima T, Omae K, Ogawa H, Shirasu H, Kito Y, Yoshida Y, Hamauchi S, Todaka A, Machida N, Yokota T, Yamazaki K, Fukutomi A, Onozawa Y, Yasui H. Risk factors for esophageal fistula in thoracic esophageal squamous cell carcinoma invading adjacent organs treated with definitive chemoradiotherapy: a monocentric casecontrol study. BMC Cancer. 2018; 18:573-579.

34. Fujita H. A history of surgery for locally-advanced (T4) cancer of the thoracic esophagus in Japan and a personal perspective. Ann Thorac Cardiovasc Surg. 2013; 19:409415.

35. Yano M, Tsujinaka T, Shiozaki H, Inoue M, Doki Y, Yamamoto M, Tanaka E, Inoue T, Monden M. Concurrent chemotherapy (5-fluorouracil and cisplatin) and radiation therapy followed by surgery for T4 squamous cell carcinoma of the esophagus. J Surg Oncol. 1999; 70:2532.

36. Takeuchi M, Kawakubo H, Mayanagi S, Yoshida K, Irino T, Fukuda K, Nakamura R, Wada N, Takeuchi H, Kitagawa Y. The benefits of docetaxel plus cisplatin and 5-fluorouracil induction therapy in conversion to curative treatment for locally advanced esophageal squamous cell carcinoma. World J Surg. 2019; 43:2006-2015.

37. Hashimoto M, Shirakawa Y, Maeda N, Tanabe S, Noma K, Sakurama K, Katsui K, Nishizaki M, Fujiwara T. Induction chemoradiotherapy including docetaxel, cisplatin, and 5-fluorouracil for locally advanced esophageal cancer. Esophagus. 2020; 17:127-134. 
38. Makino T, Yamasaki M, Miyazaki Y, Wada N, Takahashi T, Kurokawa Y, Nakajima K, Takiguchi S, Mori M, Doki Y. Utility of initial induction chemotherapy with 5-fluorouracil, cisplatin, and docetaxel (DCF) for T4 esophageal cancer: a propensity score-matched analysis. Dis Esophagus. 2017; 31:1-7.

39. Satake H, Tahara M, Mochizuki S, et al. A prospective, multicenter phase I/II study of induction chemotherapy with docetaxel, cisplatin and fluorouracil (DCF) followed by chemoradiotherapy in patients with unresectable locally advanced esophageal carcinoma. Cancer Chemother Pharmacol. 2016; 78:91-99.

40. Nakajima M, Muroi H, Kikuchi M, Yamaguchi S, Sasaki K, Tsuchioka T, Takei Y, Shibasaki I, Fukuda H, Kato H. Salvage esophagectomy combined with partial aortic wall resection following thoracic endovascular aortic repair. Gen Thorac Cardiovasc Surg. 2018; 66:736-743.
41. Makino T, Yasuda T, Shiraishi O, Shiozaki H. Aortic stentgrafting facilitates a successful resection after neoadjuvant treatment of a cT4 esophageal cancer. J Thorac Cardiovasc Surg. 2014; 148:e211-e212.

Received October 15, 2021; Revised April 29, 2021; Accepted May 10, 2021.

Released online in J-STAGE as advance publication May 16, 2021.

\section{*Address correspondence to:}

Kazuhiko Yamada, Department of Surgery, National Center for Global Health and Medicine, 1-21-1 Toyama, Shinjuku-ku, Tokyo 162-8655, Japan.

E-mail:kayamada@hosp.ncgm.go.jp 